\title{
A Revision of Clausius Work On the Second Law. 2. On the Values of Clausius Transformations
}

\author{
José C. Iñiguez
}

Centro de Investigación en Termodinámica y Fenómenos Auto-Organizativos, CITER, Av. Panamericana 357, Agua Prieta Sonora, México 84200, Mexico

E-mail: iniguez@c2i2.com

Received: 19 October 1999 / Accepted: 26 October 1999 / Published: 30 October 1999

\begin{abstract}
The values associated to Clausius transformations are obtained through an analysis different to that of Clausius inasmuch it does not introduce any assumption or condition as to what the combined value of the transformations in a reversible cyclical process should be. The values thus obtained allow for the identification of the flaw in Clausius work leading to the inconsistency discussed in part I of this series.
\end{abstract}

Keywords: quality and value of a transformation, Clausius flaw.

\section{Introduction}

According to Clausius two different kinds of transformations are produced in a cyclical process..."a transformation from heat into work (or vice versa) and a transformation from heat of a higher temperature to heat of a lower (or vice versa)" [1], and based on ..." the condition that in every reversible process of the kind given above the two transformations that take place must be equal in magnitude but of opposite sign, so that their algebraical sum is zero"[2], Clausius obtained the values of the said transformations, results that eventually led him to his law of increasing entropy, which according to his results is to be taken as an alternate expression of the second law of thermodynamics.In what follows the values of the above mentioned transformations will be obtained independently of any assumption regarding its combined value for reversible cyclical processes.

(C) 1999 by MDPI (http://www.mdpi.org). Reproduction is permitted for noncommercial purposes. 


\section{The Values of the Transformations}

Consider an isolated system comprised of two thermal reservoirs, one at temperature $T_{h}$ and the other at $T_{c}$, where $T_{h}>T_{c}$. Consider further the flow of a unit of heat (u) from the hot reservoir. Once $\mathrm{u}$ ends up in the cold reservoir, the capability for work production it originally had in relation to that cold reservoir, i.e. $\left(T_{h}-T_{c}\right) / T_{h}$, has been wasted. Furthermore, its capacity for further work production will be lesser the lesser the temperature of the cold reservoir in which it ends up being absorbed. Now, if this capability of heat for motive power generation, or in general, "the availability of energy for external purposes" [3], is designated as its quality, it should be obvious that for the case at hand the quality loss of $\mathrm{u},-\Delta \overline{\mathrm{C}}$, will be directly proportional to the amount of lost work and inversely proportional to the temperature of its cold reservoir, i.e.

$$
\Delta \overline{\mathrm{C}}=\frac{\mathrm{T}_{\mathrm{c}}-\mathrm{T}_{\mathrm{h}}}{\mathrm{T}_{\mathrm{c}} \mathrm{T}_{\mathrm{h}}}
$$

Now, the fact that the quality change experienced by $Q$ units of heat will be $Q$ times greater than the one experienced by one unit permits writing eq. 1 as follows:

$$
\Delta \mathrm{C}=\mathrm{Q} \frac{\mathrm{T}_{\mathrm{c}}-\mathrm{T}_{\mathrm{h}}}{\mathrm{T}_{\mathrm{c}} \mathrm{T}_{\mathrm{h}}}
$$

It should also be realized that the process just analyzed is that of the irreversible transference of heat from $\mathrm{T}_{\mathrm{h}}$ to $\mathrm{T}_{\mathrm{c}}$. The result expressed in eq. 2 corresponds thus, in Clausius terminology, to the quality change of the irreversible transformation of an amount of heat $\mathrm{Q}$ from $\mathrm{T}_{\mathrm{h}}$ to $\mathrm{T}_{\mathrm{c}}$, and as such, it will be represented as follows:

$$
\Delta \mathrm{C}\left[\mathrm{Q}\left(\mathrm{T}_{\mathrm{h}}\right) \rightarrow \mathrm{Q}\left(\mathrm{T}_{\mathrm{c}}\right)\right]_{\text {irr }}=\mathrm{Q} \frac{\mathrm{T}_{\mathrm{c}}-\mathrm{T}_{\mathrm{h}}}{\mathrm{T}_{\mathrm{c}} \mathrm{T}_{\mathrm{h}}}
$$

In order to determine now the quality changes associated to the transformation of heat into work or vice versa let us consider one cycle in the operation of the reversible cyclical process known as Carnot's reversible engine. Once the cycle has been completed, two transformations have occurred: the transformation of an amount of heat $Q^{\prime}$ from the hot reservoir at $T_{h}$ to the cold reservoir at $T_{c}$ : $\left[\mathrm{Q}^{\prime}\left(\mathrm{T}_{\mathrm{h}}\right) \rightarrow \mathrm{Q}^{\prime}\left(\mathrm{T}_{\mathrm{c}}\right)\right]_{\text {rev }}$ and the transformation into work $(\mathrm{w})$ of an amount of heat $\mathrm{Q}$ at $\mathrm{T}_{\mathrm{h}}$ : $\left[\mathrm{Q}\left(\mathrm{T}_{\mathrm{h}}\right) \rightarrow \mathrm{w}\right]_{\mathrm{rev}}$. This operation is represented in Figure 1(a). We will proceed now, say by friction, to irreversibly transform the work previously produced $(\mathrm{w})$ into an equivalent amount of heat $(\mathrm{Q})$ that will end up in the cold reservoir at $\mathrm{T}_{\mathrm{c}}$. This transformation, $\left[\mathrm{w} \rightarrow \mathrm{Q}\left(\mathrm{T}_{\mathrm{c}}\right)\right]_{\text {irr }}$, is depicted in Figure 1(b). Now, these operations can be reduced to two transformations of heat from $T_{h}$ to $T_{c}$, one being reversible and the other irreversible, as shown in Figure 1(c). The reversible transformation, [Q' $\left(\mathrm{T}_{\mathrm{h}}\right) \rightarrow$ $\left.\mathrm{Q}^{\prime}\left(\mathrm{T}_{\mathrm{c}}\right)\right]_{\mathrm{rev}}$, is the one produced by the reversible cyclical evolution of the working substance in Carnot's engine. The irreversible one arises from the combination of the two transformations: $\left[\mathrm{Q}\left(\mathrm{T}_{\mathrm{h}}\right) \rightarrow \mathrm{w}\right]_{\mathrm{rev}}$ and $\left[\mathrm{w} \rightarrow \mathrm{Q}\left(\mathrm{T}_{\mathrm{c}}\right)\right]_{\mathrm{irr}}$, i.e.

$$
\left[\mathrm{Q}\left(\mathrm{T}_{\mathrm{h}}\right) \rightarrow \mathrm{w}\right]_{\mathrm{rev}}+\left[\mathrm{w} \rightarrow \mathrm{Q}\left(\mathrm{T}_{\mathrm{c}}\right)\right]_{\mathrm{irr}}=\left[\mathrm{Q}\left(\mathrm{T}_{\mathrm{h}}\right) \rightarrow \mathrm{Q}\left(\mathrm{T}_{\mathrm{c}}\right)\right]_{\mathrm{irr}}
$$

the irreversible label attached to the above resulting transformation is due to the fact that any irreversibility arising in an otherwise reversible process renders the combination irreversible. 


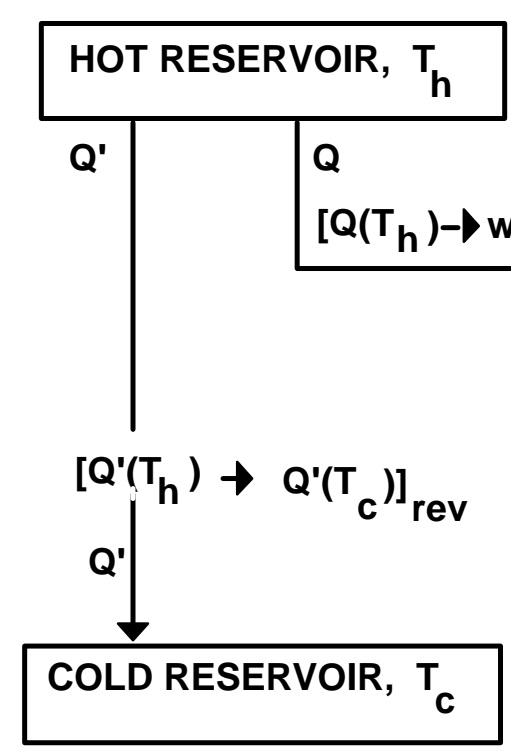

(a)

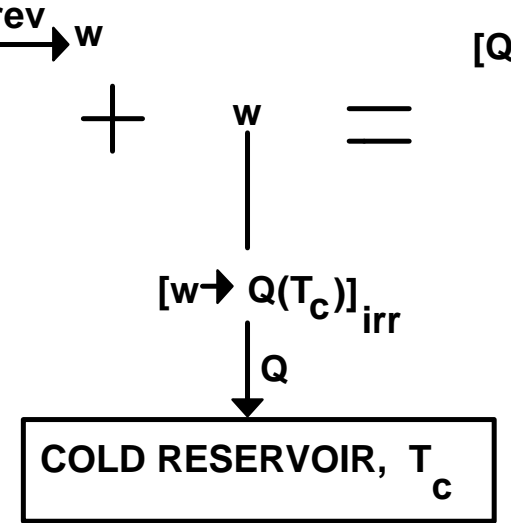

(b)

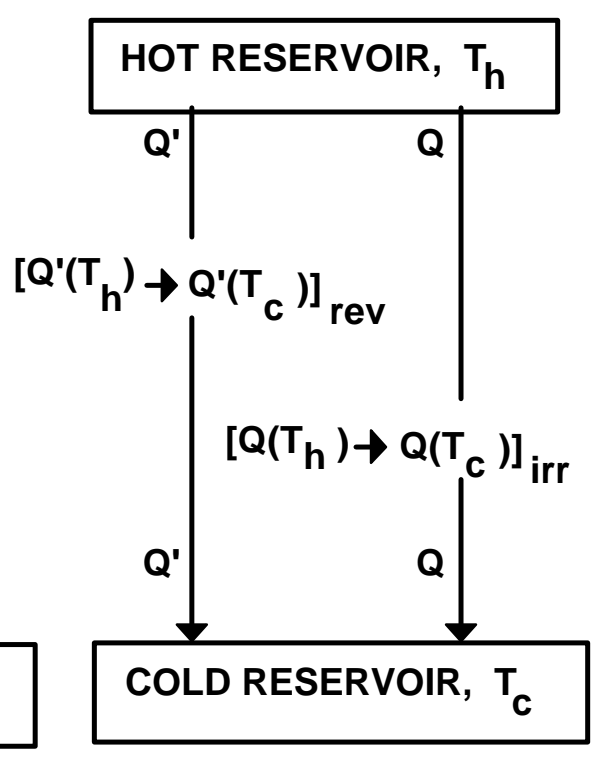

(c)

Figure 1. The combination of the transformations associated to the reversible operation of a Carnot engine (a), with the irreversible transformation of work into heat (b), is reduced to two transformations of heat from $\mathrm{T}_{\mathrm{h}}$ to $\mathrm{T}_{\mathrm{c}}$ : one reversible and one irreversible, (c).

In terms of quality changes, and based on the results expressed by eq. 3 , we will write eq. 4 as follows:

$$
\Delta \mathrm{C}\left[\mathrm{Q}\left(\mathrm{T}_{\mathrm{h}}\right) \rightarrow \mathrm{w}\right]_{\mathrm{rev}}+\Delta \mathrm{C}\left[\mathrm{w} \rightarrow \mathrm{Q}\left(\mathrm{T}_{\mathrm{c}}\right)\right]_{\text {irr }}=\frac{\mathrm{Q}}{\mathrm{T}_{\mathrm{h}}}-\frac{\mathrm{Q}}{\mathrm{T}_{\mathrm{c}}}
$$

Now, with regard to transformation $\left[\mathrm{w} \rightarrow \mathrm{Q}\left(\mathrm{T}_{\mathrm{c}}\right)\right]_{\mathrm{irr}}$, it is at once seen that the quality change to it associated must be proportional to the quantity of heat generated and beyond this it can only depend on its temperature $\mathrm{T}_{\mathrm{c}}$. We may therefore, in eq. 5, make the following identification:

$$
\Delta \mathrm{C}\left[\mathrm{w} \rightarrow \mathrm{Q}\left(\mathrm{T}_{\mathrm{c}}\right)\right]_{\text {irr }}=-\frac{\mathrm{Q}}{\mathrm{T}_{\mathrm{c}}}
$$

consequently, it follows that:

$$
\Delta \mathrm{C}\left[\mathrm{Q}\left(\mathrm{T}_{\mathrm{h}}\right) \rightarrow \mathrm{w}\right]_{\mathrm{rev}}=\frac{\mathrm{Q}}{\mathrm{T}_{\mathrm{h}}}
$$

this last equation can also be written as:

$$
\Delta \mathrm{C}\left[\mathrm{w} \rightarrow \mathrm{Q}\left(\mathrm{T}_{\mathrm{h}}\right)\right]_{\mathrm{rev}}=-\frac{\mathrm{Q}}{\mathrm{T}_{\mathrm{h}}}
$$

which, when applied to the transformation of work into heat of temperature $T_{c}$, takes the following form:

$$
\Delta \mathrm{C}\left[\mathrm{w} \rightarrow \mathrm{Q}\left(\mathrm{T}_{\mathrm{c}}\right)\right]_{\mathrm{rev}}=-\frac{\mathrm{Q}}{\mathrm{T}_{\mathrm{c}}}
$$


In comparing now eqs. 6 and 9 it can be seen that the quality change of these two transformations is the same. In other words, irrespective of the mechanism by which it is accomplished, the degradation of work into heat carries with it a quality decrease equal to $-\mathrm{Q} / \mathrm{T}_{\mathrm{c}}$, i.e.

$$
\Delta \mathrm{C}\left[\mathrm{w} \rightarrow \mathrm{Q}\left(\mathrm{T}_{\mathrm{c}}\right)\right]_{\mathrm{rev}}=\Delta \mathrm{C}\left[\mathrm{w} \rightarrow \mathrm{Q}\left(\mathrm{T}_{\mathrm{c}}\right)\right]_{\mathrm{irr}}=-\frac{\mathrm{Q}}{\mathrm{T}_{\mathrm{c}}}
$$

By making use of the result expressed by eq. 10, we can write eq. 5 as follows:

$\Delta \mathrm{C}\left[\mathrm{Q}\left(\mathrm{T}_{\mathrm{h}}\right) \rightarrow \mathrm{w}\right]_{\mathrm{rev}}+\Delta \mathrm{C}\left[\mathrm{w} \rightarrow \mathrm{Q}\left(\mathrm{T}_{\mathrm{c}}\right)\right]_{\mathrm{rev}}=\frac{\mathrm{Q}}{\mathrm{T}_{\mathrm{h}}}-\frac{\mathrm{Q}}{\mathrm{T}_{\mathrm{c}}}$

And it is regarding this equation that a most important observation is to be made, an observation that is intimately related to Clausius analysis flaw and that consists in the realization that, at difference of eq. 5, equation 11 cannot be re-expressed, in terms of the transformations it subsumes, in an equation similar to eq. 4 , i.e.

$$
\left[\mathrm{Q}\left(\mathrm{T}_{\mathrm{h}}\right) \rightarrow \mathrm{w}\right]_{\mathrm{rev}}+\left[\mathrm{w} \rightarrow \mathrm{Q}\left(\mathrm{T}_{\mathrm{c}}\right)\right]_{\mathrm{rev}} \neq\left[\mathrm{Q}\left(\mathrm{T}_{\mathrm{h}}\right) \rightarrow \mathrm{Q}\left(\mathrm{T}_{\mathrm{c}}\right)\right]_{\mathrm{rev}}
$$

and the reason for this is that while the sequence of transformations represented in the left hand side of eq. 4 effectively assures that the heat given off by the hot reservoir at $\mathrm{T}_{\mathrm{h}}$ is finally absorbed by the cold reservoir at $\mathrm{T}_{\mathrm{c}}$, thus defining an irreversible heat transfer process; the sequence of transformations represented in the left hand side of eq. 12 is insufficient to define a process that effectively transport in a reversible fashion to the cold reservoir, the heat given off by the hot reservoir, and this is so because between transformations $\left[\mathrm{Q}\left(\mathrm{T}_{\mathrm{h}}\right) \rightarrow \mathrm{w}\right]_{\mathrm{rev}}$ and $\left[\mathrm{w} \rightarrow \mathrm{Q}\left(\mathrm{T}_{\mathrm{c}}\right)\right]_{\mathrm{rev}}$ there exists a discontinuity, a missing step that does not allow the reversible heat transfer process to actually occur, this missing step being an adiabatic and reversible expansion [A.R.E.], or compression for the reverse process. The inclusion of the [A.R.E.] step will transform eq.12 into an equation which be the actual representation of the process by means of which an amount of heat $\mathrm{Q}$ is reversibly transferred from a hot to a cold reservoir, i.e.

$\left[\mathrm{Q}\left(\mathrm{T}_{\mathrm{h}}\right) \rightarrow \mathrm{w}\right]_{\mathrm{rev}}+[$ A.R.E. $]+\left[\mathrm{w} \rightarrow \mathrm{Q}\left(\mathrm{T}_{\mathrm{c}}\right)\right]_{\mathrm{rev}}=\left[\mathrm{Q}\left(\mathrm{T}_{\mathrm{h}}\right) \rightarrow \mathrm{Q}\left(\mathrm{T}_{\mathrm{c}}\right)\right]_{\mathrm{rev}}$

Equations 5 and 11, it has to be pointed out, are indeed algebraically significant: They express what the sum of the quality changes for the transformations there shown amounts to. The concatenation of the transformations in they contained however, might, as in eq. 4, or might not, as in eq.12, be the expression of a physical process. In other words, and for the case at hand, it can then be said that the concatenation of two opposing heat-work transformations, i.e. $[\mathrm{Q} \rightarrow \mathrm{w}]+[\mathrm{w} \rightarrow \mathrm{Q}]$, is not always a condition sufficient for defining a heat transfer process.

Now, this [A.R.E.] connecting step above referred will lead us to what we have called the thermomechanical transformation. The discussion of the nature of this transformation and the value to it associated will be done in what follows.

\section{The Thermomechanical Transformation}

Consider the occurrence of a reversible and isothermal expansion at $\mathrm{T}_{\mathrm{h}}$. Once the expansion is complete an amount of heat $(\mathrm{Q})$ has been converted into work $(\mathrm{w})$. Transformation $\left[\mathrm{Q}\left(\mathrm{T}_{\mathrm{h}}\right) \rightarrow \mathrm{w}\right]_{\mathrm{rev}}$ has 
taken place producing a quality change equal to $\mathrm{Q} / \mathrm{T}_{\mathrm{h}}$. Consider similarly the occurrence of the same process at temperature $\mathrm{T}_{\mathrm{c}}, \mathrm{T}_{\mathrm{h}}>\mathrm{T}_{\mathrm{c}}$. At the end of this expansion an amount of heat $(\mathrm{Q})$ equal to that involved in the previous expansion is converted into work $(w)$. Transformation $\left[Q\left(T_{c}\right) \rightarrow w\right]_{\text {rev }}$ has taken place producing a quality change equal to $\mathrm{Q} / \mathrm{T}_{\mathrm{c}}$. The initial states of these expansions were chosen in such a way that the final states, represented in Figures 2(a) and 2(b) could be connected by an adiabatic and reversible process.
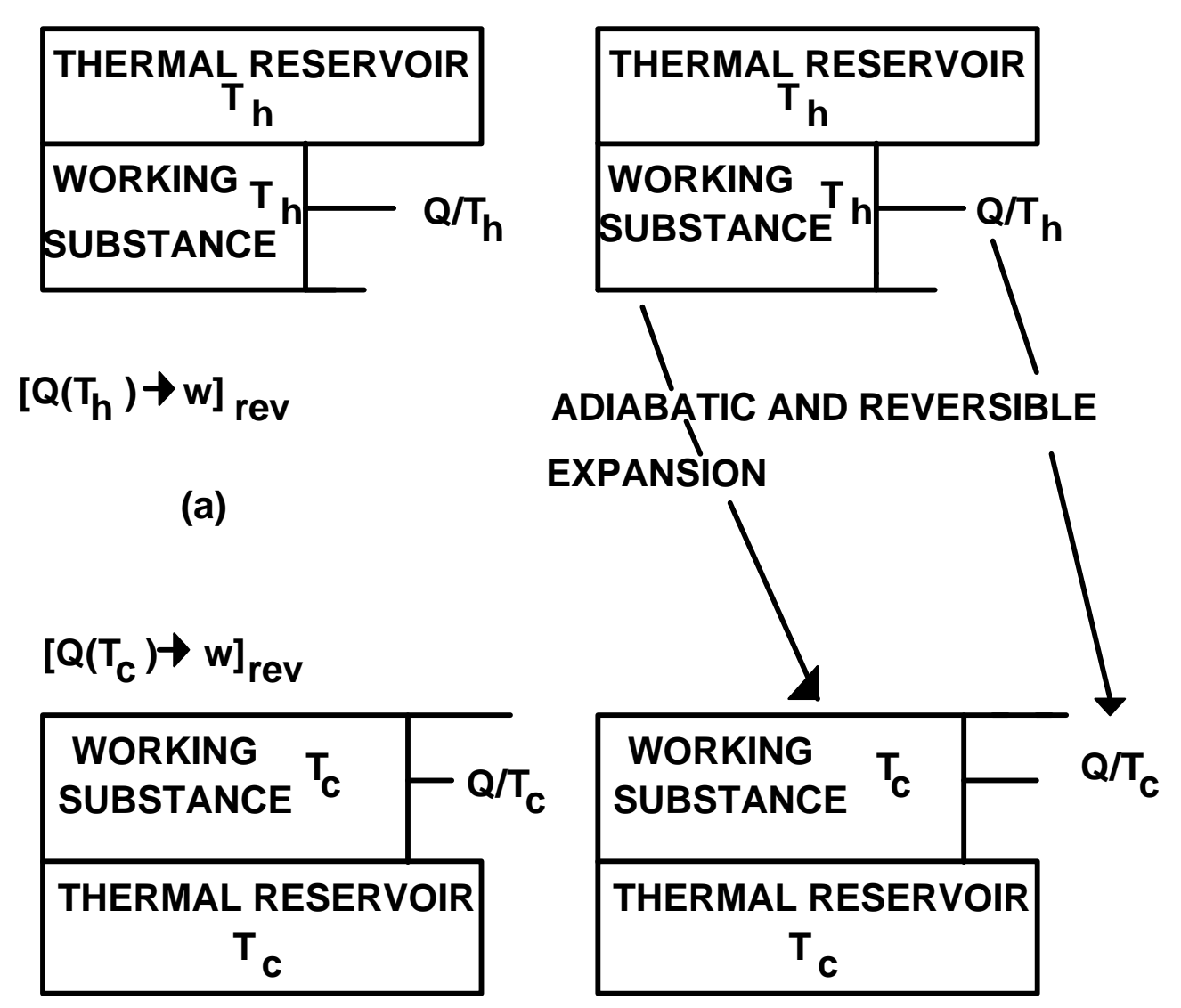

(b)

(c)

Figure 2. The replacement of the final state of transformation $\left[Q\left(T_{h}\right) \rightarrow w\right]_{\text {rev }}$ by the final state of transformation $\left[\mathrm{Q}\left(\mathrm{T}_{\mathrm{c}}\right) \rightarrow \mathrm{w}\right]_{\mathrm{rev}}$ through an adiabatic and reversible expansion defines the thermomechanical transformation $\left[\mathrm{Qw}\left(\mathrm{T}_{\mathrm{h}}\right) \rightarrow \mathrm{Qw}\left(\mathrm{T}_{\mathrm{c}}\right)\right]_{\mathrm{rev}}$.

Consider now the situation depicted in Figure 2(c). The states there represented are identical with those represented in Figures 2(a) and 2(b) respectively. Let us now carry on the indicated adiabatic and reversible expansion. At the beginning of the said process the quality was $Q / T_{h}$. At the end of it the quality is $\mathrm{Q} / \mathrm{T}_{\mathrm{c}}$. The adiabatic and reversible expansion has allowed the substitution of the state represented in Figure 2(a) by that state represented in Figure 2(b), and in doing so a quality change equal to 
$\mathrm{Q} / \mathrm{T}_{\mathrm{c}}-\mathrm{Q} / \mathrm{T}_{\mathrm{h}}$ has also taken place. This substitution of states depicted in Figure 2, which is actually the transformation of a transformation, is what will be designated as a reversible thermomechanical transformation. It will be represented as $\left[\mathrm{Qw}\left(\mathrm{T}_{\mathrm{i}}\right) \rightarrow \mathrm{Qw}\left(\mathrm{T}_{\mathrm{f}}\right)\right]_{\text {rev }}$, being the quality change to it associated, as discussed above, given by the following expression:

$$
\Delta \mathrm{C}\left[\mathrm{Qw}\left(\mathrm{T}_{\mathrm{i}}\right) \rightarrow \mathrm{Qw}\left(\mathrm{T}_{\mathrm{f}}\right)\right]_{\mathrm{rev}}=\frac{\mathrm{Q}}{\mathrm{T}_{\mathrm{f}}}-\frac{\mathrm{Q}}{\mathrm{T}_{\mathrm{i}}}
$$

It can now be realized that through this transformation track is kept on the changes sustained by the quality produced through transformations $[\mathrm{Q}(\mathrm{T}) \rightarrow \mathrm{w}]_{\text {rev }}$, or remaining after transformations $[\mathrm{w} \rightarrow \mathrm{Q}(\mathrm{T})]_{\text {rev }}$ have taken place, as the final states of those transformations are displaced in the temperature scale through adiabatic and reversible trajectories.

With this transformation identified and its value determined we will proceed now to the evaluation of the quality change associated to the reversible transformation of an amount of heat $\mathrm{Q}$ from $\mathrm{T}_{\mathrm{h}}$ to $\mathrm{T}_{\mathrm{C}}$ : $\left[\mathrm{Q}\left(\mathrm{T}_{\mathrm{h}}\right) \rightarrow \mathrm{Q}\left(\mathrm{T}_{\mathrm{c}}\right)\right]_{\text {rev }}$, which can be accomplished through the following sequence:

$$
\left[\mathrm{Q}\left(\mathrm{T}_{\mathrm{h}}\right) \rightarrow \mathrm{Q}\left(\mathrm{T}_{\mathrm{c}}\right)\right]_{\mathrm{rev}}=\left[\mathrm{Q}\left(\mathrm{T}_{\mathrm{h}}\right) \rightarrow \mathrm{w}\right]_{\mathrm{rev}}+\left[\mathrm{Qw}\left(\mathrm{T}_{\mathrm{h}}\right) \rightarrow \mathrm{Qw}\left(\mathrm{T}_{\mathrm{c}}\right)\right]_{\mathrm{rev}}+\left[\mathrm{w} \rightarrow \mathrm{Q}\left(\mathrm{T}_{\mathrm{c}}\right)\right]_{\mathrm{rev}}
$$

the quality change of which can be obtained by substituting in eq. 15 the quality changes associated to the transformations there shown. When this is done the following expression is obtained:

$$
\Delta \mathrm{C}\left[\mathrm{Q}\left(\mathrm{T}_{\mathrm{h}}\right) \rightarrow \mathrm{Q}\left(\mathrm{T}_{\mathrm{c}}\right)\right]_{\mathrm{rev}}=\frac{\mathrm{Q}}{\mathrm{T}_{\mathrm{h}}}+\left(\frac{\mathrm{Q}}{\mathrm{T}_{\mathrm{c}}}-\frac{\mathrm{Q}}{\mathrm{T}_{\mathrm{h}}}\right)-\frac{\mathrm{Q}}{\mathrm{T}_{\mathrm{c}}}
$$

which reduces to

$$
\Delta \mathrm{C}\left[\mathrm{Q}\left(\mathrm{T}_{\mathrm{h}}\right) \rightarrow \mathrm{Q}\left(\mathrm{T}_{\mathrm{c}}\right)\right]_{\mathrm{rev}}=0
$$

The reversible transformation of heat from high to low temperature or vice versa carries with it a quality change equal to zero.

If a comparison is now made between our quality changes and Clausius values it will be realized that, with the exception to be noted below, one is the negative of the other. Let us then on these grounds define a property of a transformation which will be called its value $(\mathrm{V})$, in such a way that:

$$
\mathrm{V}=-\Delta \mathrm{C}
$$

Thus, if the occurrence of a transformation is accompanied by a decrease in quality, the value of the said transformation will increase in the same amount or vice versa.

In terms of their value, eqs. $3,7,10,14$, and 17 can be written as follows:

$$
\begin{aligned}
& \mathrm{V}\left[\mathrm{Q}\left(\mathrm{T}_{\mathrm{h}}\right) \rightarrow \mathrm{Q}\left(\mathrm{T}_{\mathrm{c}}\right)\right]_{\text {irr }}=-\frac{\mathrm{Q}}{\mathrm{T}_{\mathrm{h}}}+\frac{\mathrm{Q}}{\mathrm{T}_{\mathrm{c}}} \\
& \mathrm{V}\left[\mathrm{Q}\left(\mathrm{T}_{\mathrm{h}}\right) \rightarrow \mathrm{w}\right]_{\mathrm{rev}}=-\frac{\mathrm{Q}}{\mathrm{T}_{\mathrm{h}}} \\
& \mathrm{V}\left[\mathrm{w} \rightarrow \mathrm{Q}\left(\mathrm{T}_{\mathrm{c}}\right)\right]_{\mathrm{rev}}=\mathrm{V}\left[\mathrm{w} \rightarrow \mathrm{Q}\left(\mathrm{T}_{\mathrm{c}}\right)\right]_{\text {irr }}=\frac{\mathrm{Q}}{\mathrm{T}_{\mathrm{c}}} \\
& \mathrm{V}\left[\mathrm{Qw}\left(\mathrm{T}_{\mathrm{h}}\right) \rightarrow \mathrm{Qw}\left(\mathrm{T}_{\mathrm{c}}\right)\right]=\frac{\mathrm{Q}}{\mathrm{T}_{\mathrm{h}}}-\frac{\mathrm{Q}}{\mathrm{T}_{\mathrm{c}}}
\end{aligned}
$$




$$
\mathrm{V}\left[\mathrm{Q}\left(\mathrm{T}_{\mathrm{h}}\right) \rightarrow \mathrm{Q}\left(\mathrm{T}_{\mathrm{c}}\right)\right]_{\mathrm{rev}}=0
$$

The exception noted above refers of course to the disagreement existing between our result and that of Clausius regarding the reversible transformation of heat from high to low temperature or vice versa. This disagreement is the matter of the discussion that follows.

\section{The Flaw in Clausius Analysis}

According to Clausius, [4]:

The generation out of work of the quantity of heat $\mathrm{Q}$ of temperature $\tau$ has the equivalence value $\mathrm{Q} / \tau$; and the transference of the quantity of heat $\mathrm{Q}$ from temperature $\mathrm{T}_{1}$ to temperature $T_{2}$ has the Equivalence-Value $Q\left(\frac{1}{\tau_{2}}-\frac{1}{\tau_{1}}\right)$ in which $\tau$ is a function of temperature independent of the kind of process by which the transformation is accomplished...

If we write this last expression of the foregoing section in the form $\frac{\mathrm{Q}}{\tau_{2}}-\frac{\mathrm{Q}}{\tau_{1}}$, we see that the passage of the quantity of heat $Q$ from temperature $T_{1}$ to $T_{2}$ has the same equivalencevalue as a double transformation of the first kind, viz. the transformation of the quantity $\mathrm{Q}$ from heat of temperature $T_{1}$ into work and again out of work into heat of temperature $T_{2}$. The examination of the question how far this external agreement has its actual foundation in the nature of the process would here be out of place; but in any case we may, in the mathematical determination of the Equivalence-Value, treat every transference of heat, in whatever way it may have taken place, as a combination of two opposite transformations of the first kind.

It is in this statement where Clausius analysis flaw can be located since, as we have already shown, a combination of two opposite transformations of the first kind do not always define a heat transfer process. Clausius assertion is indeed true for the irreversible transformation of heat as eq. 4 shows. It, however, is not true for the reversible heat transference because, as was discussed at length before, in addition to the two reversible opposite transformations of the first kind, a linking step in the form of an adiabatic and reversible processes is also needed, but when this step is included the value for the reversible heat transference turns out to be zero and not $\frac{\mathrm{Q}}{\mathrm{T}_{2}}-\frac{\mathrm{Q}}{\mathrm{T}_{1}}$ as Clausius contends.

\section{Final Comment}

The herein demonstrated fact that the values of the transformations occurring in a reversible cyclical process are not equal in magnitude but of opposite sign has a wide variety of consequences, ranging from the breaking of the supposed inviolability of the law of increasing entropy and the need to the re- 
adjust the currently accepted criteria for thermodynamic spontaneity and equilibrium, to the possibility of developing a new approach for the study of the so called self-organizing phenomena. All of these will be dealt with in the following paper of this series.

\section{References and Notes}

1. Clausius, R. The Mechanical Theory of Heat; MacMillan: London, 1879; p 91.

2. Clausius, R. The Mechanical Theory of Heat; MacMillan: London, 1879; $\mathrm{p} 98$.

3. Lewis, G.N.; Randall, M. Thermodynamics; McGraw-Hill: New York, 1961; 77.

4. Clausius, R. The Mechanical Theory of Heat; MacMillan: London, 1879; p 101.

(C) 1999 by MDPI (http://www.mdpi.org). Reproduction is permitted for noncommercial purposes. 